\title{
Arthroscopic Versus Open Rotator Cuff Repair: Fellowship-Trained Orthopaedic Surgeons Prefer Arthroscopy and Self-Report a Lower Complication Rate
}

\author{
Blane C. Kelly, M.D., David S. Constantinescu, M.D., William Pavlis, B.S., and \\ Alexander R. Vap, M.D.
}

Purpose: To evaluate whether fellowship training had an effect on the practice pattern and complication rates among Part II examinees of the American Board of Orthopaedic Surgery (ABOS) for rotator cuff repair (RCR) from 2007-2017. Methods: The ABOS database was queried for arthroscopic (Current Procedural Terminology [CPT] code 29827) and open/mini-open (CPT codes: 23410, 23412) RCR performed from 2007-2017. Excluded were procedures that did not included CPT codes 29827, 23410, 23412. A comparison between arthroscopic and open/mini-open use as well as selfreported complications were assessed based on recorded fellowship training. Results: A total of 31,907 RCR were reported over the past 10 years (2007-2017). The percentage of RCR procedures performed using arthroscopic technique vs open/mini-open varied among surgeons who completed one fellowship: Sports Medicine $(92.5 \%$ arthroscopy; $7.5 \%$ mini/ open), Shoulder \& Elbow (91.3 \% arthroscopy; 8.7\% mini/open), and Hand \& Upper Extremity (69.6 \% arthroscopy; 30.4 $\%$ open). Total complication rates varied among surgeons who completed one fellowship: Sports Medicine (11.5\%), Shoulder \& Elbow (13.5 \%), and Hand \& Upper Extremity (13.4\%). Surgeons completing one fellowship in either Sports Medicine, Shoulder \& Elbow, Hand \& Upper Extremity all reported significantly lower complication rates using arthroscopic over mini/open technique $(P<.001)$. Conclusions: Among ABOS Part II examinees completing a Sports Medicine, Shoulder and Elbow or Hand and Upper Extremity fellowship, Sports Medicine trained surgeons had significantly greater rates of performing arthroscopic over open RCR and significantly lower self-reported intraoperative complication rates. Clinical Relevance: Understanding the effects of fellowship training may guide mentors and future trainees.

$\mathbf{T}$ he surgical management of rotator cuff repair (RCR) is performed either arthroscopically or by an open/mini-open technique. In the past, the literature

From Virginia Commonwealth University, Richmond, Virginia (B.C.K., A.R.V.); and University of Miami, Miami, Florida (D.S.C., W.P.), U.S.A.

The authors report the following potential conflicts of interest or sources of funding: The Department of Orthopaedic Surgery from our institution (Virginia Commonwealth University). Full ICMJE author disclosure forms are available for this article online, as supplementary material.

The abstract of this manuscript was accepted and presented at the following: International Society of Arthroscopy, Knee Surgery and Orthopaedic Sports Medicine, Cancun, Mexico, May 12-16, 2019.

Received March 12, 2020; accepted September 2, 2021.

Address correspondence to David S. Constantinescu, M.D., University of Miami, 1611 NW 12th Ave \#303, Miami, FL 33136. E-mail: david. constantinescu93@gmail.com

(C) 2021 THE AUTHORS. Published by Elsevier Inc. on behalf of the Arthroscopy Association of North America. This is an open access article under the CC BY-NC-ND license (http://creativecommons.org/licenses/by-nc-nd/4.0/). 2666-061X/20362

https://doi.org/10.1016/j.asmr.2021.09.001 showed discrepancies over whether arthroscopic or open/mini-open techniques were more common for RCR. ${ }^{1-4}$ Previously, this led to the technique for performing RCR to be based on the surgeon's preference. ${ }^{5-9}$ However, a recent demonstration using the American Board of Orthopaedic Surgery (ABOS) database proved an increasing use of arthroscopic RCR techniques as well as a lower complication rate over open/mini-open RCR. ${ }^{10}$ Orthopaedic surgeons are increasingly becoming fellowship trained, ${ }^{11}$ and the training resources throughout fellowship influence the practice patterns of RCR. ${ }^{12}$ This gives rise to the question of whether fellowship training affects practice patterns and complication rates of RCR.

The purpose of this study was to evaluate whether fellowship training had an effect on the practice pattern and complication rates among Part II examinees of the ABOS for RCR from 2007 to 2017. The hypothesis was that fellowships that traditionally involve more training with arthroscopy would perform arthroscopic RCR 


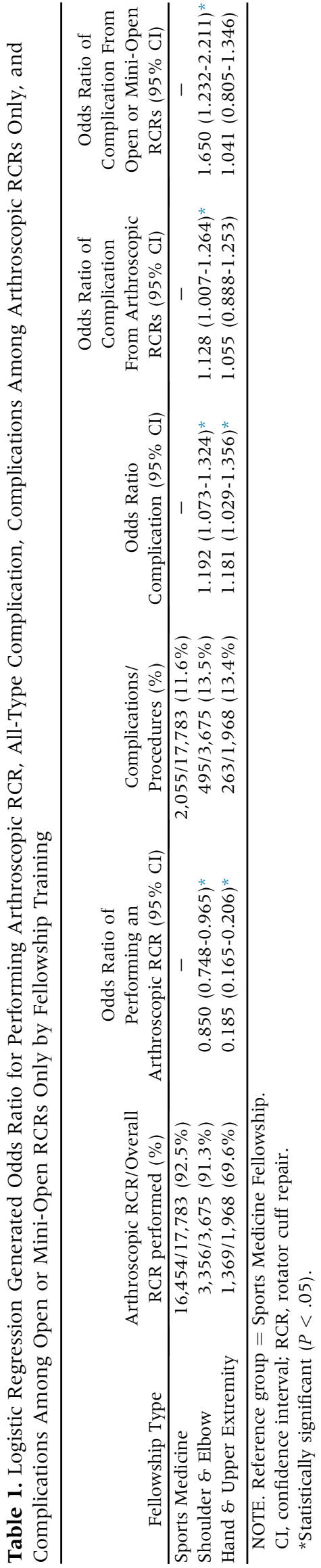

more often than open/mini-open RCR and that complication rates would vary among the fellowships.

\section{Methods}

This research protocol was reviewed by the institutional review board at the institution where the study was performed and was exempted. Candidates applying for Part II examination are informed by the ABOS that the deidentified data submitted as part of the process of board certification may be used for research purposes.

\section{Data Collection}

The ABOS database consists of information selfreported by applicants in preparation to the Part II (oral) Examination. All candidates have passed the written Part 1 board examination after completing orthopedic surgery residency. As part of the oral certification process, candidates submit data for each surgery performed over a 6-month period within their first 22 months of active practice.

Collected information within the ABOS consists of the procedure date, fellowship training of each surgeon, International Classification of Diseases code, Current Procedural Terminology (CPT) surgical procedural codes, age, sex, and complications (anesthetic, medical, surgical, reoperation, readmission). Each candidate enters the information based on his or her own subjective patient assessment, and no patient-derived data are included. Strengths of this database are that it includes more than 80,000 total cases each year by more than 650 surgeons.

Our requested search query from the ABOS database included all RCR procedures performed by Part II Examinees for the years 2007 to 2017 . This consisted of all of their respective cases operated during the years 2006 to 2016. The inclusion criteria were arthroscopic RCR (CPT code 29827) and open/mini-open RCR (CPT codes 23410 and 23412) procedures and respective reported complications for each. Excluded were procedures that did not included CPT codes 29827, 23410, and 23412 .

\section{Statistical Methods}

Data were analyzed to determine the number of RCRs performed over the 10-year period and descriptive statistics were calculated for all data. The rate of both arthroscopic RCR and open/mini-open RCR as a percentage of total cases for 3 different fellowships (Sports Medicine, Shoulder \& Elbow, Hand \& Upper Extremity) was determined. Data were then analyzed for cumulative complication rates for each of the 3 fellowships. A further analysis within each of the 3 fellowships was done to compare complication rates between arthroscopic versus open/mini-open. A $\chi^{2}$ and logistic regression analysis was performed to determine the association between fellowship type and the rate of 
Fig 1. Cumulative complication rates (anesthetic, medical, surgical, reoperation, and readmission) of arthroscopic and open rotator cuff repairs based on the total number of rotator cuff surgeries and complications reported to the ABOS for specific fellowship-trained orthopaedic surgeons. *Statistically significant difference between arthroscopic and open complication rates $\left(P<.05, \chi^{2}\right.$ analysis $)$ for Sports Medicine, shoulder and Elbow, and Hand and Upper Extremity.

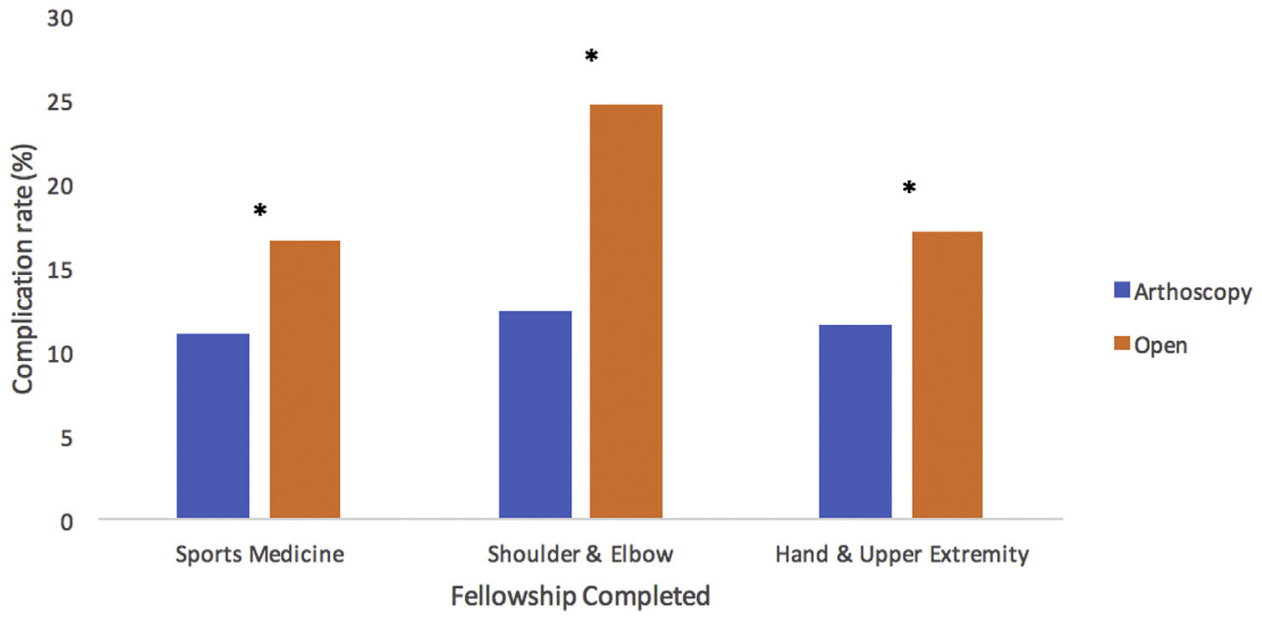

arthroscopic RCR repair and overall complication rate. An additional $\chi^{2}$ analysis was used to determine the significance of difference in complication rate of arthroscopic RCR and open or mini-open RCR by fellowship type. The top 5 most commonly performed procedures based on grouped CPT codes were analyzed for the 3 fellowships to compare the complication rates with performing an isolated RCR, using both arthroscopic and open techniques. Each reported complication was considered as a percentage of the total arthroscopic RCR or open/mini-open RCR. The $\chi^{2}$ analysis was performed to determine significance of complication rates for each fellowship between arthroscopic RCR and open/mini-open RCR. Data analysis was performed using Microsoft Excel (Microsoft, Redmond, WA) and IBM SPSS software (IBM Corp., Armonk, NY). A $P$ value of $<.05$ was considered statistically significant.

Table 2. Five Most Common Concomitant Procedures Performed Arthroscopically in Addition to Rotator Cuff Repair and Their Incidence, Total Complication Rate, and Statistical Significance to Isolated Rotator Cuff Repair Based on CPT Codes For Sports Medicine, Shoulder \& Elbow, and Hand \& Upper Extremity Fellowships

\begin{tabular}{|c|c|c|c|}
\hline CPT & $\begin{array}{c}\text { Rate of Concomitant } \\
\text { Procedures Performed (\%) }\end{array}$ & Total Complication Rate (\%) & Significance to Isolated RCR ( $P$ Value) \\
\hline \multicolumn{4}{|c|}{ Sports Medicine - Arthroscopic } \\
\hline 29827 & $12 \%(2024 / 16454)$ & $9.2 \%$ & \\
\hline $29824,29826,29827$ & $8 \%(1344 / 16454)$ & $9.4 \%$ & .8 \\
\hline $29822,29826,29827$ & $7 \%(1134 / 16454)$ & $8.7 \%$ & .67 \\
\hline $29823,29826,29827$ & $6 \%(920 / 16454)$ & $9.8 \%$ & .61 \\
\hline 29827 & $12 \%(424 / 3356)$ & $11.1 \%$ & \\
\hline 29826,29827 & $14 \%(454 / 3356)$ & $5.9 \%$ & $.01^{*}$ \\
\hline $29823,29826,29827$ & $8 \%(268 / 3356)$ & $7.8 \%$ & .16 \\
\hline $29826,29827,29828$ & $6 \%(207 / 3356)$ & $6.2 \%$ & .72 \\
\hline 29827,29828 & $4 \%(130 / 3356)$ & $18.5 \%$ & $.03^{*}$ \\
\hline 29824, 29826, 29827 & $3 \%(115 / 3356)$ & $17.4 \%$ & .07 \\
\hline $29823,29826,29827$ & $8 \%(107 / 1369)$ & $10.3 \%$ & .9 \\
\hline $29822,29826,29827$ & $7 \%(92 / 1369)$ & $12.0 \%$ & .75 \\
\hline $29826,29827,29828$ & $4 \%(48 / 1369)$ & $2.1 \%$ & .06 \\
\hline
\end{tabular}

NOTE. CPT procedure legend: arthroscopic RCR (29827). Subacromial decompression with partial acromioplasty, with or without coracoacromial release (29826). Distal claviculectomy including distal articular surface (29824). Debridement, limited (29822). Debridement, extensive (29823). Arthroscopic surgical biceps tenodesis (29828).

CPT, Current Procedural Terminology; RCR, rotator cuff repair.

*Statistical significance $\left(P<.05 \chi^{2}\right.$ analysis $)$. 
Table 3. Five Most Common Concomitant Procedures Performed Open/Mini-Open in Addition to Rotator Cuff Repair and Their Incidence, Total Complication Rate, and Statistical Significance To Isolated Rotator Cuff Repair Based on CPT Codes for Sports Medicine, Shoulder \& Elbow, and Hand \& Upper Extremity Fellowships

\begin{tabular}{|c|c|c|c|}
\hline $\begin{array}{r}\mathrm{CPT} \\
\end{array}$ & $\begin{array}{c}\text { Rate of Concomitant } \\
\text { Procedures Performed (\%) }\end{array}$ & Total Complication Rate $(\%)$ & Significance to Isolated RCR ( $P$ Value $)$ \\
\hline \multicolumn{4}{|l|}{ Sports Medicine - Open } \\
\hline 23410 or 23412 & $15 \%(196 / 1329)$ & $7.7 \%$ & \\
\hline 23412,23430 & $3 \%(44 / 1329)$ & $15.9 \%$ & .08 \\
\hline 23410,23430 & $3 \%(41 / 1329)$ & $14.6 \%$ & .15 \\
\hline 23410,29826 & $3 \%(38 / 1329)$ & $13.2 \%$ & .27 \\
\hline 23410 or 23412 & $13 \%(43 / 319)$ & $20.9 \%$ & \\
\hline 23410,23430 & $5 \%(15 / 319)$ & $13.3 \%$ & 0.5 \\
\hline 23130,23410 & $4 \%(12 / 319)$ & $8.3 \%$ & .3 \\
\hline 23410,23630 & $3 \%(10 / 319)$ & $20 \%$ & .9 \\
\hline 23412,23430 & $3 \%(10 / 319)$ & $10 \%$ & .4 \\
\hline $23120,23130,23405,23412,29823$ & $3 \%(8 / 319)$ & $50 \%$ & .08 \\
\hline $23412,29824,29826$ & $3 \%(17 / 599)$ & $0 \%$ & .08 \\
\hline 23410,29826 & $3 \%(16 / 599)$ & $18.75 \%$ & .8 \\
\hline 23410,23430 & $2 \%(13 / 599)$ & $23 \%$ & .5 \\
\hline
\end{tabular}

NOTE. CPT procedure legend: Open RCR (23412 or 23410). Subacromial decompression with partial acromioplasty, with or without coracoacromial release (29826). Tenodesis of long tendon of biceps (23430). Acromionectomy (23130). Greater humeral tuberosity fracture treatment (23630). Partial claviculectomy (23120). Tenotomy; single (23405). Debridement, extensive (29823). Debridement, limited (29822). Distal claviculectomy including distal articular surface (29824).

CPT, Current Procedural Terminology; RCR, rotator cuff repair.

Statistical significance $\left(P<.05 \chi^{2}\right.$ analysis $)$.

\section{Results}

During the years 2007 to 2017, there were a total of 31,907 RCRs. Average patient age was 56.8 years old. Among patients, $58.4 \%$ were male and $41.6 \%$ were female. The percentage of RCR procedures performed using arthroscopic technique versus open/mini-open technique varied among surgeons who completed one fellowship. Sports Medicine-trained surgeons performed arthroscopic RCR at rates significantly greater $(92.5 \%)$ than both Shoulder \& Elbow-trained $(91.3 \%)$ and Hand \& Upper Extremity-trained $(69.6 \%)$ surgeons $(P<.05)$. Shoulder $\&$ Elbow-trained surgeons also performed arthroscopic RCR at rates significantly greater than Hand \& Upper Extremity-trained surgeons $(P<.05)$. The odds ratios of performing an arthroscopic repair by fellowship type are summarized in Table 1.

Total complication rates varied among surgeons who completed one fellowship. Sports Medicine-trained surgeons reported significantly lower $(P<.05)$ complication rates $(11.6 \%)$ than both Shoulder $\delta$ Elbow-trained $(13.5 \%)$ and Hand $\&$ Upper Extremity-trained $(13.4 \%)$ surgeons. There was no significant difference in complication rate between Shoulder \& Elbow-trained and Hand $\&$ Upper
Extremity-trained surgeons. The odds ratios for reporting complications by fellowship are summarized in Table 1. Surgeons completing 1 fellowship in either Sports Medicine, Shoulder \& Elbow, or Hand \& Upper Extremity all had statistically significant lower complication rates in arthroscopy versus open technique $(P<.05)$ (Fig 1). The odds ratio of complication from arthroscopic RCR and open or mini-open RCR are summarized in Table 1. Among only arthroscopic RCRs, Sports Medicine-trained surgeons had the lowest complication rate $(11.1 \%)$; however, the rate was only significantly lower than the rate of complications among Shoulder \& Elbow-trained surgeons (12.4\%) $(P<.05)$. For open or mini-open RCRs, both Sports Medicine-trained and Hand \& Upper Extremity-trained surgeons reported complication rates significantly lower than Shoulder $\&$ Elbow-trained surgeons $(P<.05)$.

The top 5 most commonly performed procedures based on grouped CPT codes were analyzed for 3 fellowships (Sports Medicine, Shoulder \& Elbow, Hand \& Upper Extremity) to compare the complication rates with performing an isolated RCR, using both arthroscopic (Table 2) and open (Table 3) techniques. In the majority of concomitant procedures performed 
arthroscopically, no statistically significant difference in complication rate was observed. For Sports Medicine and Shoulder \& Elbow fellowships, performing arthroscopic biceps tenodesis increased the complication rate versus isolated arthroscopic RCR. For Shoulder $\&$ Elbow and Hand \& Upper Extremity fellowships, performing arthroscopic subacromial decompression lowered the complication rate versus isolated arthroscopic RCR. For open procedures, no concomitant procedure had any significant effect on the complication rate in comparison to isolated open RCR.

\section{Discussion}

The most important finding of this study is that practice patterns and complication rates for rotator cuff repair vary among surgeons who have completed different fellowships. ABOS Part II examinees who have completed a sports medicine fellowship perform the greatest rates of arthroscopic procedures $(92.5 \%)$ and have the lowest complication rates for RCR $(11.5 \%)$. Both rates are significantly different $(P<.05)$ from those for Shoulder $\&$ Elbow-trained and Hand $\&$ Upper Extremity-trained surgeons.

Proficiency using an arthroscopic procedure is strongly related to training throughout residency and fellowship. ${ }^{8,12-14}$ Vitale et al. ${ }^{12}$ found that surgeons that completed Sports Medicine or Shoulder \& Elbow fellowships have more experience using arthroscopy and are most likely to show a preference for all-arthroscopic repair. These findings are similar to ours in that Sports Medicine and Shoulder \& Elbow fellowships had a greater rate of arthroscopic procedures in comparison to Hand and Upper Extremity fellowships. Furthermore, a loss in performance level of arthroscopy has been demonstrated if it is not continuously implemented in training programs. ${ }^{15,16}$ This may explain why surgeons who performed a greater proportion of arthroscopic repairs subsequently have lower complication rates than those who perform arthroscopy less frequently. The use of arthroscopic simulator training models has been demonstrated to improve arthroscopic technique performance. ${ }^{17-22}$ This may translate to increased competency in the operating room and is a potential avenue to gain skill throughout residency training. ${ }^{23}$

Although previous literature did not establish a definitive difference in outcomes between arthroscopic versus open/mini-open RCR repair, ${ }^{9,24-27}$ the use of the ABOS database demonstrated that arthroscopic RCR is increasingly performed over open RCR and has a lower complication rate. ${ }^{10}$ One possible explanation for this is that greater RCR competency is achieved with the repair method that the surgeon performs more often. However, this finding may also be confounded as the ABOS database does not specify between rotator cuff properties and an open repair method may have been required on larger and more complex tears. This finding held true throughout specific fellowships, as this study demonstrated that all 3 fellowships, Sports Medicine, Shoulder \& Elbow, and Hand \& Upper Extremity, showed significantly lower complication rates using an arthroscopic technique versus open/mini-open. The Sports Medicine fellowship group had the overall lowest complication rate and was statistically significant compared with other fellowships.

Among all arthroscopic RCRs, the difference in selfreported complication rate among Sports Medicineand Hand \& Upper Extremity-trained surgeons was not statistically significant. This suggests the overall difference in RCR between the 2 fellowships could be due to differences in proportion of RCRs performed arthroscopically. Efforts to improve adoption of arthroscopic RCR technique among Hand \& Upper Extremity fellows could potentially create significant improvements in overall complication rates.

A potential confounder that may impact complication rates is the difficulty of the surgical procedure. Intraoperative complications can primarily be attributed to failure in device, osteochondral, or soft tissue. ${ }^{28,29}$ Interestingly, our analysis of the most commonly performed concomitant procedures in comparison with open or arthroscopic RCR alone, only performance of concomitant biceps tenodesis by Sports Medicine and Should \& Elbow-trained surgeons increased reported complication rate.

This study is able to establish a difference in surgical trends across fellowships. ABOS Part II examinees who complete a Sports Medicine fellowship perform arthroscopic procedures most frequently and additionally have the lowest complication rates over Shoulder $\&$ Elbow and Hand \& Upper Extremity fellowship trained surgeons. As rotator cuff repair gains popularity as a costeffective treatment in the United States, decreasing intraoperative complication rates will further contribute to this procedure's success. ${ }^{30,31}$ The increasing number of subspecialized and fellowship trained orthopaedic surgeons allows for increased likelihood for successful rotator cuff surgeries with the lowest complication rates. ${ }^{11,32}$

\section{Limitations}

We recognize several limitations to this study. First, this study is a retrospective evaluation of a large database. Second, no clinical information regarding patient medical history, cuff tear size, or presurgical characteristics were provided by the ABOS database. Therefore, there could be a selection bias with the open/mini-open technique used on larger and more difficult to repair rotator cuff tears in an unhealthier patient population. Third, a reporting bias may also be present, as complications may not be consistently or uniformly reported across all of the applicants. Future research could analyze the impact of presurgical 
characteristics and complexity of rotator cuff tears on these results as well as differences in likelihood to selfreport a complication based on fellowship type.

\section{Conclusions}

Among ABOS Part II examinees completing a Sports Medicine, Shoulder and Elbow, or Hand and Upper Extremity fellowship, Sports Medicine-trained surgeons had significantly greater rates of performing arthroscopic over open RCR and significantly lower self-reported intraoperative complication rates

\section{References}

1. Colvin AC, Egorova N, Harrison AK, Moskowitz A, Flatow EL. National trends in rotator cuff repair. $J$ Bone Joint Surg Am 2012;94:227-233.

2. Dunn WR, Schackman BR, Walsh C, et al. Variation in orthopaedic surgeons' perceptions about the indications for rotator cuff surgery. J Bone Joint Surg Am 2005;87: 1978-1984.

3. Huang R, Wang S, Wang Y, Qin X, Sun Y. Systematic review of all-arthroscopic versus mini-open repair of rotator cuff tears: A meta-analysis. Sci Rep 2016;6:22857.

4. Yamaguchi K, Levine WN, Marra G, Galatz LM, Klepps S, Flatow EL. Transitioning to arthroscopic rotator cuff repair: The pros and cons. Instr Course Lect 2003;52:81-92.

5. Mohtadi NG, Hollinshead RM, Sasyniuk TM, Fletcher JA, Chan DS, Li FX. A randomized clinical trial comparing open to arthroscopic acromioplasty with mini-open rotator cuff repair for full-thickness rotator cuff tears: Diseasespecific quality of life outcome at an average 2-year follow-up. Am J Sports Med 2008;36:1043-1051.

6. Morse K, Davis AD, Afra R, Kaye EK, Schepsis A, Voloshin I. Arthroscopic versus mini-open rotator cuff repair: A comprehensive review and meta-analysis. Am J Sports Med 2008;36:1824-1828.

7. Williams G, Kraeutler MJ, Zmistowski B, Fenlin JM. No difference in postoperative pain after arthroscopic versus open rotator cuff repair. Clin Orthop Relat Res 2014;472: 2759-2765.

8. Middleton RM, Vo A, Ferguson J, et al. Can surgical trainees achieve arthroscopic competence at the end of training programs? A cross-sectional study highlighting the impact of working time directives. Arthroscopy 2017:33:1151-1158.

9. Liu J, Fan L, Zhu Y, Yu H, Xu T, Li G. Comparison of clinical outcomes in all-arthroscopic versus mini-open repair of rotator cuff tears: A randomized clinical trial. Medicine (Baltimore) 2017;96:e6322.

10. Kelly BC, Constantinescu DS, Vap AR. Arthroscopic and open or mini-open rotator cuff repair trends and complication rates among American Board of Orthopaedic Surgeons Part II examinees (2007-2017). Arthroscopy 2019;35:3019-3024.

11. Horst PK, Choo K, Bharucha N, Vail TP. Graduates of orthopaedic residency training are increasingly subspecialized: A review of the American Board of Orthopaedic Surgery Part II Database. J Bone Joint Surg Am 2015;97:869-875.
12. Vitale MA, Kleweno CP, Jacir AM, Levine WN, LU Bigliani, Ahmad CS. Training resources in arthroscopic rotator cuff repair. J Bone Joint Surg Am 2007;89: 1393-1398.

13. Martin KD, Patterson DP, Cameron KL. Arthroscopic training courses improve trainee arthroscopy skills: A simulation-based prospective trial. Arthroscopy 2016;32: 2228-2232.

14. O'Neill PJ, Cosgarea AJ, Freedman JA, Queale WS, McFarland EG. Arthroscopic proficiency: A survey of orthopaedic sports medicine fellowship directors and orthopaedic surgery department chairs. Arthroscopy 2002;18: 795-800.

15. Dunn JC, Belmont PJ, Lanzi J, Martin K, Bader J, Owens B, Waterman BR. Arthroscopic shoulder surgical simulation training curriculum: Transfer reliability and maintenance of skill over time. J Surg Educ 2015;72: $1118-1123$.

16. Howells NR, Auplish S, Hand GC, Gill HS, Carr AJ, Rees JL. Retention of arthroscopic shoulder skills learned with use of a simulator. Demonstration of a learning curve and loss of performance level after a time delay. J Bone Joint Surg Am 2009;91:1207-1213.

17. Angelo RL, Pierre PS, Tauro J, et al. A proficiency-based progression simulation training curriculum to acquire the skills needed in performing arthroscopic Bankart and rotator cuff repairs-implementation and impact. Arthroscopy 2021;37:1099-1106.e5.

18. Cychosz CC, Tofte JN, Johnson A, Gao Y, Phisitkul P. Fundamentals of arthroscopic surgery training program improves knee arthroscopy simulator performance in arthroscopic trainees. Arthroscopy 2018;34:1543-1549.

19. Gandhi MJ, Anderton MJ, Funk L. Arthroscopic skills acquisition tools: an online simulator for arthroscopy training. Arthroscopy 2015:31:1671-1679.

20. Gilmer BB, Guerrero DM, Coleman NW Chamberlain AM, Warme WJ. Orthopaedic residents improve confidence and knot-tying speed with a skills course. Arthroscopy 2015;31:1343-1348.e2.

21. van der Heijden LLM, Reijman M, van der Steen MC (Marieke), Janssen RPA, Tuijthof GJM. Validation of Simendo Knee Arthroscopy Virtual Reality Simulator. Arthroscopy 2019;35:2385-2390.

22. Roberts PG, Alvand A, Gallieri M, Hargrove C, Rees J. Objectively assessing intraoperative arthroscopic skills performance and the transfer of simulation training in knee arthroscopy: A randomized controlled trial. Arthroscopy 2019;35:1197-1209.el.

23. Frank RM, Erickson B, Frank JM, et al. Utility of modern arthroscopic simulator training models. Arthroscopy 2014;30:121-133.

24. Bayle X, Pham T-T, Faruch M, Gobet A, Mansat P, Bonnevialle N. No difference in outcome for open versus arthroscopic rotator cuff repair: A prospective comparative trial. Arch Orthop Trauma Surg 2017;137:1707-1712.

25. Bishop J, Klepps S, Lo I, Bird J, Gladstone J, Flatow EL. Cuff integrity after arthroscopic versus open rotator cuff repair: A prospective study. J Shoulder Elbow Surg 2006;15: 290-299.

26. Jensen AR, Cha PS, Devana SK, Ishmael C, Di Pauli von Treuheim T, D'Oro A, Wang JC, McAllister DR, 
Petrigliano FA. Evaluation of the trends, concomitant procedures, and complications with open and arthroscopic rotator cuff repairs in the Medicare population. Orthop J Sports Med 2017;5:2325967117731310.

27. Kang L, Henn F, Tashjian R, Green A. Early outcome of arthroscopic rotator cuff repair: a matched comparison with mini-open rotator cuff repair. Arthroscopy 2007;23: 573-582.e2.

28. Audigé L, Flury M, Müller AM, ARCR CES Consensus Panel, Durchholz H. Complications associated with arthroscopic rotator cuff tear repair: Definition of a core event set by Delphi consensus process. J Shoulder Elbow Surg 2016;25:1907-1917.
29. Desai VS, Southam BR, Grawe B. Complications following arthroscopic rotator cuff repair and reconstruction. JBJS Rev 2018;6:e5.

30. Iyengar JJ, Samagh SP, Schairer W, Singh G, Valone FH, Feeley BT. Current trends in rotator cuff repair: Surgical technique, setting, and cost. Arthroscopy 2014;30:284-288.

31. Mather RC, Koenig L, Acevedo D, Dall TM, Gallo P, Romeo A, Tongue J, Williams G Jr. The societal and economic value of rotator cuff repair. J Bone Joint Surg Am 2013;95:1993-2000.

32. Morrell NT, Mercer DM, Moneim MS. Trends in the orthopedic job market and the importance of fellowship subspecialty training. Orthopedics 2012;35:e555-e560. 